\title{
Construction of pelvic floor muscle rehabilitation training program for patients undergoing laparoscopic radical prostatectomy
}

\author{
Zheng-Zheng Ma ${ }^{1 \#}$, Hong-Bing Zhang ${ }^{2 \#}$, Mei-E Niu ${ }^{3}$, Yan-Hong Ding ${ }^{4}$, Yan Zhou ${ }^{1}$, Qi Yang $^{2}$, \\ Jia-Li Wang ${ }^{1}$, Xiao-Wen Zhu ${ }^{1}$, Chun-Ya Qian ${ }^{1}$, Min Su $^{5}$ \\ ${ }^{1}$ Department of Urology, the First Affiliated Hospital of Soochow University, Suzhou, China; ${ }^{2}$ Department of Physical Medicine and Rehabilitation, \\ the First Affiliated Hospital of Soochow University, Suzhou, China; ${ }^{3}$ Department of Nursing, the First Affiliated Hospital of Soochow University, \\ Suzhou, China; ${ }^{4}$ Department of Urology, Suzhou Municipal Hospital, Suzhou, China; ${ }^{5}$ Department of Physical Medicine and Rehabilitation, Dushu \\ Lake Hospital affiliated of Soochow University, Suzhou, China \\ Contributions: (I) Conception and design: All authors; (II) Administrative support: C Qian, M Su; (III) Provision of study materials or patients: Z \\ Ma, H Zhang; (IV) Collection and assembly of data: Z Ma, H Zhang, X Zhu, Y Zhou; (V) Data analysis and interpretation: Z Ma, H Zhang; (VI) \\ Manuscript writing: All authors; (VII) Final approval of manuscript: All authors. \\ \#These authors contributed equally to this work. \\ Correspondence to: Min Su. Department of Physical Medicine and Rehabilitation, Dushu Lake Hospital affiliated of Soochow University, Suzhou \\ 215100, China. Email: sumin@suda.edu.cn; Chun-Ya Qian. Department of Urology, the First Affiliated Hospital of Soochow University, Suzhou \\ 215006, China. Email: qianchunya01@163.com.
}

Background: Laparoscopic radical prostatectomy (LRP) is the standard treatment for early localized $\mathrm{PCa}$, of which urinary incontinence is the most common postoperative complication. Pelvic floor muscle rehabilitation training is recognized as the first line of intervention measures, but the existing rehabilitation training programs are not clear in the formulation process, the content is not unified, and the clinical operability is not strong. In order to better guide clinical pelvic floor muscle rehabilitation training after LRP and prevent and control urinary incontinence, this study constructed a pelvic floor muscle rehabilitation training program for LRP patients.

Methods: Literature analysis, qualitative interview, and an expert group meeting method were used to form the draft of pelvic floor muscle rehabilitation training program for LRP patients. On this basis, after 2 rounds of Delphi expert consultation, the research team modified and improved the program.

Results: The consultation experts involved in the 2 rounds were the same, 15 questionnaires were sent out, and 15 were recovered with an effective recovery of $100 \%$. The expert authority coefficient was 0.87. In the second round of consultation, Kendall's harmony coefficient was $0.14(\mathrm{P}<0.001)$, the mean coefficient of variation of expert opinion was $0.07(\mathrm{P}<0.001)$, and the mean value of importance assigned to each item was 4.53-5.00 points. Finally, the pelvic floor muscle rehabilitation training program for LRR patients was formed. Including rehabilitation training evaluation, rehabilitation training advanced time and content, rehabilitation training form of three first-level indicators, 12 second-level indicators, 53 third-level indicators.

Conclusions: The pelvic floor muscle rehabilitation training program for LRP patients developed in this study is scientific, reliable, safe and feasible, which can provide reference for clinical pelvic floor muscle rehabilitation training after LRP and prevention and control of urinary incontinence.

Keywords: Prostate cancer (PCa); laparoscopic radical prostatectomy (LRP); pelvic floor muscle rehabilitation; nursing; program

Submitted Nov 02, 2021. Accepted for publication Jan 20, 2022.

doi: $10.21037 /$ tcr-21-2738

View this article at: https://dx.doi.org/10.21037/tcr-21-2738 


\section{Introduction}

Prostate cancer $(\mathrm{PCa})$ is the most common urinary tumor in males in China (1). With the promotion of "Healthy China Action", residents' awareness of PCa screening is constantly improving, and early diagnosis and treatment of PCa have become the mainstream trend (2,3). Laparoscopic radical prostatectomy (LRP) is the standard treatment for early localized PCa $(4,5)$, but almost all patients will experience urinary incontinence after catheter removal (6), with an incidence of $96.7 \%$. The recovery rate fluctuates between $30 \%$ and $90 \% 1$ year after surgery $(7,8)$. Studies have shown that although urinary incontinence does not immediately endanger patients' lives, it has a significant psychological impact and will cause social function defects to varying degrees (9). Pelvic floor muscle rehabilitation training is a first-line intervention for the prevention and treatment of urinary incontinence recognized by clinical guidelines (10), and its short-term effective rate can reach $50-70 \%$, while a certain amount of training must be completed to achieve effectiveness $(11,12)$. Pelvic floor muscle rehabilitation training includes Kegel exercises, pelvic floor muscle rehabilitation exercises, pelvic floor biofeedback training, pelvic floor electrical stimulation, acupuncture treatment, and so on (13-16). Kegel exercises and pelvic floor muscle rehabilitation can be done at home due to their simplicity and safety. Therefore, most of the existing pelvic floor muscle rehabilitation training programs for LRP patients incorporate Kegel exercises alone or on the basis of Kegel exercise combined with pelvic floor muscle rehabilitation exercise. However, the existing rehabilitation training program has some shortcomings, such as unclear formulation process, inconsistent content, and weak clinical operation, on account of which it fails to play a full role in clinical practice. In view of this, this study standardized and detailed the effectiveness evaluation, start time, course of treatment, specific operation methods, and frequency of pelvic floor muscle rehabilitation training for LRP patients, and constructed a pelvic floor muscle rehabilitation training program for LRP patients, providing reference for the clinical implementation of pelvic floor muscle rehabilitation training after LRP and the prevention and control of urinary incontinence.

\section{Methods}

\section{Research group establishment}

The research team consisted of 6 expert members and
2 project researchers. The expert members included 2 urologists, 2 nurses, and 2 rehabilitation therapists with the following credentials: working years $(22.50 \pm 9.01) ; 1$ undergraduate, 2 masters, 3 doctors; all held senior titles. The expert members were mainly responsible for guiding the design of the project and quality control of the research. The 2 project researchers were masters of nursing and rehabilitation, mainly responsible for literature research, compilation of consultation questionnaire, expert selection, distribution and recovery of questionnaire, and collation and analysis of consultation results. The study conformed to the provisions of the Declaration of Helsinki (as revised in 2013), and was approved by the Institutional Review Board of The First Affiliated Hospital of Soochow University [approval number: (2021)336].

\section{Draft formation of pelvic floor muscle rehabilitation training program for patients undergoing $L R P$}

Through literature review, qualitative interview, and expert group discussion, the first draft of pelvic floor muscle rehabilitation training program for LRP patients was formed. (I) Literature review: based on evidencebased nursing, the literature about pelvic floor muscle rehabilitation training after LRP was searched by computer, and the quality of the literature was evaluated, the level of evidence was classified and the level of recommendation was determined. A total of 12 studies were included, including 3 guidelines, 1 evidence summary, 6 systematic evaluations, and 2 original research papers. A total of 13 pieces of recommended evidence were summarized, of which 7 pieces were grade A and 6 pieces were grade B. The guidelines were evaluated using the Appraisal of Guidelines for Research and Evaluation II (AGREE II). Systematic evaluation and expert consensus were conducted using the corresponding evaluation criteria [2016] of The Australian Joanna Briggs Institute Evidence-based Health Care Centre (https://jbi.global/). The quality of the original literature was evaluated according to the literature type (17). (II) Qualitative interview: Through interviews with 8 experts and 8 patients in related fields, the current situation of urinary incontinence and pelvic floor muscle rehabilitation training of patients after LRP was elucidated. After analysis, 6 themes are extracted: (i) almost all participants had urinary incontinence after catheter removal. (ii) Urinary incontinence seriously affects the quality of life of patients. (iii) Some patients do not know how to contract the pelvic floor muscles, which results in losing the best time to 
recover from urinary incontinence. (iv) The effect of pelvic floor muscle rehabilitation training was not significant in some patients, and the duration of urinary incontinence symptoms lasted more than 6 months after surgery. (v) The pelvic floor muscle rehabilitation training only adopts Kegel exercise, which is monotonous with random frequency. (vi) Medical staff for the whole process of patient guidance and supervision are insufficient. (vii) Some patients do not have WeChat, resulting in low promotion and utilization of WeChat information. It was suggested that how to improve the effect of pelvic floor muscle rehabilitation training should be considered when constructing the program, and systematic guidance and standard program should be constructed. (III) Expert group meeting: literature review and qualitative interviews were conducted to identify gaps between the best evidence and clinical practice, and a draft of the pelvic floor muscle rehabilitation training program was constructed after discussion at expert group meetings.

\section{The determination the pelvic floor muscle rehabilitation training program for patients undergoing $L R P$}

According to the first draft of pelvic floor muscle rehabilitation training program for LRP patients, an expert consultation questionnaire was made. The questionnaire includes research introduction, consultation form, basic information, and authority of experts. Likert grade 5 scoring method was used to correspond to $1-5$ points according to "not at all important-very important", and set "reason" and "suggestion" columns. Experts in urology clinical nursing, urology clinical medicine, and rehabilitation medicine from grade 3 and first-class hospitals in Suzhou, Nanjing, Shanghai, Nantong, and Xuzhou were selected. The selection criteria for experts included the following credentials: doctor of clinical medicine in urology, bachelor degree in clinical nursing, and rehabilitation medicine in urology; at least 10 years of professional experience; intermediate or above titles. All the experts provided informed consent to participate in the study voluntarily. Multiple rounds of expert consultation were conducted in the form of email or on-site research, and the consulting results were collated jointly by 2 project researchers. The expert group discussed and screened the indicators, and formulated the next round of expert consultation questionnaire. The screening criteria for indicators were the mean value of importance assignment $>4.00$, and the coefficient of variation $<0.25$.

\section{Statistical analysis}

The software SPSS 23.0 (IBM Corp., Armonk, NY, USA) was used for data statistical analysis in this study. The measurement data of experts' general data were expressed as mean \pm standard deviation, and the counting data were expressed as frequency and percentage. The significance score of each rehabilitation training index was expressed by mean, standard deviation, coefficient of variation, and full score rate. Expert positive coefficient was expressed by questionnaire recovery rate. The degree of expert authority was expressed by expert authority coefficient. The degree of coordination of expert opinions was expressed by coefficient of variation and Kendall harmony coefficient. A P value $<0.05$ was considered statistically significant.

\section{Results}

\section{Experts' general information}

In this study, a total of 15 experts were selected to complete 2 rounds of consultation, including 6 urological nursing experts, 5 rehabilitation experts, and 4 urological medical experts. There were 7 males and 8 females; age $(42.00 \pm 3.67)$ years old, working years $(20.33 \pm 6.58)$ years; 5 doctors, 4 masters, and 6 undergraduates; all held senior titles.

\section{Expert positive coefficient, degree of authority, degree of coordination of opinions}

The 2 rounds of consulting experts in this study were the same, 15 questionnaires were issued, and 15 were recovered, with effective recovery rate of $100 \%$ and positive coefficient of experts of $100 \%$. In the first round of consultation, 10 experts gave constructive opinions orally or in writing, and in the second round, 2 experts gave constructive opinions orally, with good participation.

The degree of expert authority was represented by the expert authority coefficient, which was the arithmetic mean of the expert's familiarity with the index and the expert's judgment basis. In this study, the expert judgment basis of the 2 rounds of consultation was 0.94 , the expert familiarity was 0.81 , and the expert authority coefficient was 0.87 $(>0.70)$, indicating that the expert authority was high.

The degree of coordination of expert opinions was expressed by Kendall harmony coefficient and variation coefficient. Kendall's harmony coefficient was 0.13 and $0.14, \mathrm{P}<0.001$. The mean coefficient of variation of expert 
opinions in the 2 rounds of consultation was 0.08 and 0.07 $(\mathrm{P}<0.001)$, indicating a high degree of coordination of expert opinions in the 2 rounds of consultation.

\section{Expert consultation results}

In the first round of expert consultation, the mean value of importance assignment of first-level indicators was 4.93-5.00 points, the coefficient of variation was $0-0.05$, and the full score rate was $93.33-100 \%$. The mean value of importance of second-level indicators ranged from 4.53 to 4.93 points, the coefficient of variation ranged from 0.05 to 0.16 , and the full score rate ranged from $60.00 \%$ to $93.33 \%$. The mean value of significance of the third-level indicators ranged from 4.33 to 5.00 points, the coefficient of variation ranged from 0 to 0.21 , and the full score rate was $53.33-100 \%$. According to the screening criteria of indicators and the opinions and suggestions of consulting experts, the following indicators were modified after discussion by the research group: the advanced names of rehabilitation training programs were added to the second-level indicators, including "rehabilitation training learning period", "rehabilitation training introductory period", "initial rehabilitation training period", "rehabilitation training middle period", and "rehabilitation training consolidation period"; thirdlevel indicators "told the patient to be in lateral decubitus position, with the evaluators fingers inserted into the anus so that they could feel the correct tightening" changed to "the patient was in lateral decubitus position", telephone follow-up "the method of teaching is oral teaching" to "the method of teaching is a combination of oral teaching and video viewing", "fly back training" changed to "superman flight training". In Kegel level 1 exercise "intensity: under the condition of relaxing the muscles of the lower limbs, abdomen and buttocks, voluntarily contract and relax the muscles around the pubic bone and coccyx (perineum and anal sphincter), contract when inhaling deeply and relax when exhaling, all for $10 \mathrm{~s}$. The above movements are conducted once" changed to "under the condition of relaxing the muscles of the lower limbs, abdomen and buttocks, voluntarily contract and relax the muscles around the pubic bone and coccyx (perineum and anal sphincter), keep breathing evenly, contract for $5 \mathrm{~s}$, relax for $10 \mathrm{~s}$, the above movements constituted one cycle". In Kegel level 2 exercise, "intensity: under the condition of relaxing the muscles of the lower limbs, abdomen and buttocks, the muscles around the pubic bone and coccyx (perineum and anal sphincter) should be voluntarily contracted and relaxed. Contract when inhaling deeply and relax when exhaling, all for $10 \mathrm{~s}$. The above movements constituted 1 cycle." changed to "under the condition of relaxing the muscles of the lower limbs, abdomen and buttocks, voluntarily contract and relax the muscles around the pubic bone and coccyx (perineum and anal sphincter), keep breathing evenly, contract and relax for $10 \mathrm{~s}$, and view the corresponding rehabilitation training video at the same time".

In the second round of expert consultation, the mean value of importance assignment of first-level indicators was 4.93-5.00 points, the coefficient of variation was $0-0.05$, and the full score rate was $93.33-100 \%$. The mean value of importance of second-level indicators ranged from 4.53 to 4.93 points, the coefficient of variation ranged from 0.05 to 0.15 , and the full score rate was $60.00-93.33 \%$. The mean value of significance of the third-level indicators ranged from 4.53 to 5.00 points, the coefficient of variation ranged from 0 to 0.21 , and the full score rate was 53.33 $100 \%$. According to the screening criteria of indicators and the opinions and suggestions of consulting experts, "rehabilitation training content is Kegel exercise level 1 + pelvic floor muscle rehabilitation exercise level 1" was changed to "rehabilitation training content is Kegel exercise Level $2+$ pelvic floor muscle rehabilitation exercise level 2 " in the learning period of rehabilitation training after discussion by the research group. In the consolidation period of rehabilitation training, "the form of outpatient face to face and telephone follow-up" was changed to "the form of outpatient face to face and telephone follow-up, with a total of 3 times of follow-up, namely, 3 weeks after removal of catheter, 6 months after surgery and 1 year after surgery". In the second round of this study, consensus was reached and expert consultation was ended. The research team members modified and improved the program, and finally formed the pelvic floor muscle rehabilitation training program for LRP patients, including rehabilitation training evaluation, rehabilitation training advanced time and content, rehabilitation training form of three firstlevel indicators, 12 second-level indicators, and 53 thirdlevel indicators. The results of the second round of expert consultation are shown in Table 1.

\section{Discussion}

\section{The pelvic floor muscle rehabilitation training program for patients with LRP is scientific and reliable}

In this study, the methods of literature analysis, qualitative 
Table 1 The results of the second round of expert consultation

\begin{tabular}{|c|c|c|c|}
\hline Indicators & $\begin{array}{l}\text { Mean of importance } \\
\text { assignment }\end{array}$ & $\begin{array}{l}\text { Variable } \\
\text { coefficient }\end{array}$ & $\begin{array}{l}\text { Percentage of ful } \\
\text { marks }\end{array}$ \\
\hline 1 Assessment of rehabilitation training & 5.00 & 0 & 100 \\
\hline 1.1 Evaluate the correctness of training methods & 5.00 & 0.14 & 66.67 \\
\hline 1.1.1 Instruct the patient to lateral decubitus position & 4.53 & 0.11 & 53.33 \\
\hline $\begin{array}{l}\text { 1.1.3 When the finger in the anus can feel a sense of contraction, the } \\
\text { method is confirmed as correct }\end{array}$ & 4.93 & 0.05 & 93.33 \\
\hline 1.2 Pelvic floor muscle strength assessment & 4.60 & 0.11 & 60.00 \\
\hline $\begin{array}{l}\text { 1.2.2 The pelvic floor muscle strength was divided into } 6 \text { grades, namely } \\
0 \sim \mathrm{V} \text {. The contraction lasted for } 0 \mathrm{~s} \text {, and the muscle strength was grade } 0 \text {. } \\
\text { The duration was } 1 \mathrm{~s} \text {, and the muscle strength was grade } \mathrm{I} \text {. And so on, for } 5 \mathrm{~s} \text {, } \\
\text { muscle strength is grade } \mathrm{V} \text {, and normal muscle strength is above grade III }\end{array}$ & 4.73 & 0.10 & 73.33 \\
\hline 1.3 Assessment of urinary incontinence & 4.80 & 0.12 & 86.67 \\
\hline $\begin{array}{l}\text { 1.3.1 The incidence of postpartum urinary incontinence was assessed using } \\
I C I Q-S F\end{array}$ & 4.60 & 0.11 & 60.00 \\
\hline $\begin{array}{l}\text { 1.3.2 The questionnaire included } 4 \text { aspects, which evaluated the frequency } \\
\text { of urinary leakage ( } 0-5 \text { points), the amount of urinary leakage ( } 0-6 \text { points), } \\
\text { the impact of urinary incontinence on quality of life ( } 0-10 \text { points), and the } \\
\text { self-diagnosis of causes of urinary incontinence. The first } 3 \text { items are graded } \\
\text { numerically, and the last } 1 \text { is not graded. The score is } 0-21 \text {, and the higher } \\
\text { the score, the more severe the urinary incontinence }\end{array}$ & 4.67 & 0.10 & 66.67 \\
\hline $\begin{array}{l}\text { 2.1.2 The teaching method is a combination of anatomical models, oral } \\
\text { teaching, and video viewing }\end{array}$ & 4.80 & 0.09 & 80.00 \\
\hline $\begin{array}{l}\text { 2.1.3 The implementation of the rehabilitation program is performed by } \\
\text { doctors, nurses, and rehabilitation therapists }\end{array}$ & 5.00 & 0 & 100 \\
\hline 2.1.4 The target audience is patients and their families & 5.00 & 0 & 100 \\
\hline 2.1.5 The form is face to face in the inpatient ward & 5.00 & 0 & 100 \\
\hline $\begin{array}{l}\text { 2.1.6 Rehabilitation training content: Kegel exercise level } 1+\text { pelvic floor } \\
\text { muscle rehabilitation exercise level } 1\end{array}$ & 4.73 & 0.10 & 73.33 \\
\hline $\begin{array}{l}2.2 \text { Introductory period of rehabilitation training: catheter removal to } 1 \text { week } \\
\text { after surgery }\end{array}$ & 4.73 & 0.10 & 73.33 \\
\hline $\begin{array}{l}\text { 2.2.1 Assess whether the patient can perform pelvic floor muscle } \\
\text { rehabilitation training and assimilate the training content at this stage }\end{array}$ & 4.93 & 0.05 & 93.33 \\
\hline
\end{tabular}

Table 1 (continued) 
Table 1 (continued)

\begin{tabular}{|c|c|c|c|}
\hline Indicators & $\begin{array}{l}\text { Mean of importance } \\
\text { Assignment }\end{array}$ & $\begin{array}{l}\text { Variable } \\
\text { coefficient }\end{array}$ & $\begin{array}{l}\text { Percentage of full } \\
\text { marks }\end{array}$ \\
\hline $\begin{array}{l}\text { 2.2.2 The method of teaching is a combination of oral teaching and video } \\
\text { viewing }\end{array}$ & 4.73 & 0.10 & 73.33 \\
\hline $\begin{array}{l}\text { 2.2.3 The implementation of the rehabilitation program is performed by } \\
\text { doctors, nurses, and rehabilitation therapists }\end{array}$ & 4.80 & 0.09 & 80.00 \\
\hline 2.2.5 The form is face to face in the outpatient department & 4.60 & 0.11 & 60.00 \\
\hline 2.2.6 Rehabilitation training content: Kegel exercise level 1 & 5.00 & 0 & 100 \\
\hline $\begin{array}{l}2.3 \text { Initiation period of rehabilitation training: catheter removal } 1 \text { to } 2 \text { weeks } \\
\text { after surgery }\end{array}$ & 4.87 & 0.07 & 86.67 \\
\hline $\begin{array}{l}\text { 2.3.2 The method of teaching is a combination of oral teaching and video } \\
\text { viewing }\end{array}$ & 4.53 & 0.14 & 60.00 \\
\hline $\begin{array}{l}\text { 2.3.3 The implementation of the rehabilitation program is performed by } \\
\text { nurses }\end{array}$ & 4.73 & 0.10 & 73.33 \\
\hline 2.3.4 The target audience is patients and their families & 4.93 & 0.05 & 93.33 \\
\hline 2.3.5 The form was telephone follow-up & 5.00 & 0 & 100 \\
\hline 2.3.6 Rehabilitation training content: Kegel exercise level 2 & 4.67 & 0.10 & 66.67 \\
\hline $\begin{array}{l}\text { 2.4 Middle stage of rehabilitation training-catheter removal } 2 \text { to } 3 \text { weeks } \\
\text { after surgery }\end{array}$ & 4.80 & 0.09 & 80.00 \\
\hline 2.4.4 The target audience is patients and their families & 5.00 & 0 & 100 \\
\hline 2.4.5 The form is home visit & 4.53 & 0.11 & 53.33 \\
\hline $\begin{array}{l}\text { 2.4.6 Rehabilitation training content: Kegel exercise level } 2+\text { pelvic floor } \\
\text { muscle rehabilitation training exercise level } 1\end{array}$ & 4.73 & 0.10 & 73.33 \\
\hline $\begin{array}{l}2.5 \text { Consolidation period of rehabilitation training - catheter removal from } \\
3 \text { weeks to } 1 \text { year post-operation }\end{array}$ & 4.80 & 0.09 & 80.00 \\
\hline $\begin{array}{l}\text { 2.5.1 Assess whether the patient can correctly identify the pelvic floor } \\
\text { muscle contraction function, whether to adhere to training and urinary } \\
\text { incontinence, and assimilate the training content of this stage }\end{array}$ & 4.60 & 0.11 & 60.00 \\
\hline 2.5.2 The method of teaching is oral teaching & 4.80 & 0.09 & 80.00 \\
\hline
\end{tabular}

Table 1 (continued) 
Table 1 (continued)

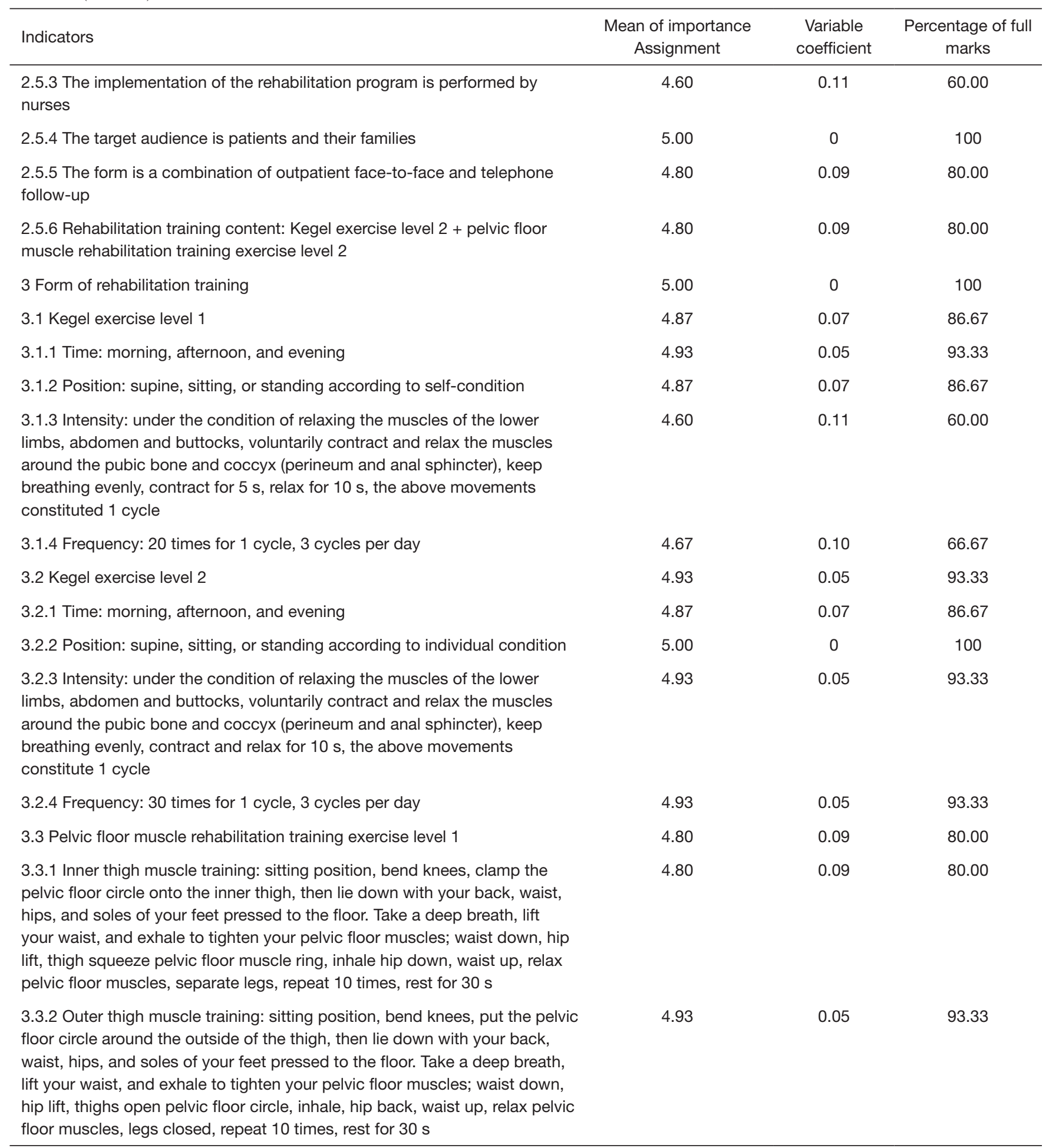

Table 1 (continued) 
Table 1 (continued)

\begin{tabular}{|c|c|c|c|}
\hline Indicators & $\begin{array}{c}\text { Mean of importance } \\
\text { assignment }\end{array}$ & $\begin{array}{l}\text { Variable } \\
\text { coefficient }\end{array}$ & $\begin{array}{c}\text { Percentage of full } \\
\text { marks }\end{array}$ \\
\hline $\begin{array}{l}\text { 3.3.3 Hip training: kneeling on the pad, clamp the pelvic floor circle to the } \\
\text { inside of your calf, then lie on your stomach, bend your knees back } 90 \\
\text { degrees, take a deep breath, exhale, tighten your pelvic floor muscles, } \\
\text { using force from your hips to squeeze your calves, exhale, open your legs } \\
\text { simultaneously. Repeat } 10 \text { times, resting for } 30 \mathrm{~s} \text { between rounds }\end{array}$ & 5.00 & 0 & 100 \\
\hline 3.4 Pelvic floor muscle rehabilitation training exercise level 2 & 4.80 & 0.09 & 80.00 \\
\hline $\begin{array}{l}\text { 3.4.1 Inner thigh muscle training: sitting position, bend knees, clamp the } \\
\text { pelvic floor circle onto the inner thigh, then lie down with your back, waist, } \\
\text { hips, and soles of your feet pressed to the floor. Take a deep breath, lift } \\
\text { your waist, and exhale to tighten your pelvic floor muscles, Waist down, hip } \\
\text { lift, thigh squeeze pelvic floor muscle ring, inhale hip down, waist up, relax } \\
\text { pelvic floor muscles, separate legs, repeat } 15 \text { times, rest for } 15 \mathrm{~s}\end{array}$ & 4.80 & 0.09 & 80.00 \\
\hline $\begin{array}{l}\text { 3.4.2 Outer thigh muscle training: sitting position, bend knees, trap the } \\
\text { pelvic floor circle around the outside of the thigh, then lie down with your } \\
\text { back, waist, hips, and soles of your feet pressed to the floor. Take a deep } \\
\text { breath, lift your waist, and exhale to tighten your pelvic floor muscles, Waist } \\
\text { down, hip lift, thighs open pelvic floor circle, inhale, hip back, waist up, relax } \\
\text { pelvic floor muscles, legs closed, repeat } 15 \text { times, rest } 15 \mathrm{~s}\end{array}$ & 4.87 & 0.07 & 86.67 \\
\hline $\begin{array}{l}\text { 3.4.3 Hip training: kneeling on the pad, clamp the pelvic floor circle to the } \\
\text { inside of your calf, then lie on your stomach, bend your knees back } 90 \\
\text { degrees, take a deep breath, exhale, tighten your pelvic floor muscles, } \\
\text { using force from your hips to squeeze your calves, exhale, open your legs } \\
\text { simultaneously. Repeat } 15 \text { times, resting for } 15 \mathrm{~s}\end{array}$ & 5.00 & 0 & 100 \\
\hline
\end{tabular}

interview, and expert group meeting were adopted to form the draft of pelvic floor muscle rehabilitation training program for LRP patients. On this basis, after Delphi expert consultation, research team members modified and improved the program, and finally established the pelvic floor muscle rehabilitation training program for LRP patients, which has sufficient theoretical basis and practical experience. The effectiveness evaluation, starting time, course of treatment, specific operation methods, and frequency of LRP patients' pelvic floor muscle rehabilitation training in studies that have been conducted within China are not clear, and there have been few studies on LRP pelvic floor muscle rehabilitation intervention of Kegel exercise combined with pelvic floor muscle rehabilitation exercise. Therefore, it is important to listen widely and seek the advice of authoritative experts in urology and rehabilitation. In this study, the effective recovery rate of the 2 rounds of expert consultation questionnaires was high, at $100 \%$. The proportion of experts who gave suggestions was $66.70 \%$ and $13.30 \%$ respectively, indicating that the experts had high enthusiasm and participation in the study. Overall, the 15 experts were $(42.00 \pm 3.67)$ years old, working years were $(20.33 \pm 6.58)$, and they held senior titles. Urology clinical nursing and rehabilitation medicine staff all held a bachelor's degree or above, and those specializing in urology clinical medicine all held a doctor's degree, which ensured their 
representation of the subject field. It is generally considered that the expert authority coefficient $\geq 0.7$ is the acceptable reliability, and the expert authority coefficient in the second round of this study was 0.87 , indicating that the expert authority is high. After the second round of consultation, the mean value of importance assigned to all indicators of the scheme was $>4.00$, and the coefficient of variation was $<0.25$, indicating a high degree of concentration of expert opinions. The significance test of Kendall's harmony coefficient of the 2 rounds of expert consultation was statistically significant $(\mathrm{P}<0.001)$, indicating that the consistency degree of experts' identification of indicators was acceptable, experts' opinions tended to be consistent, and the results were credible.

\section{The pelvic floor muscle rehabilitation training program for patients with LRP is safe and feasible}

Kegel exercises are a pelvic floor muscle training method developed by Kegel in 1948 to restore pelvic floor function through pelvic floor muscle exercises. Its function is to enhance the pelvic floor muscles to support the bladder and urethra, and increase the strength of the urethral sphincter. When the abdominal pressure suddenly increases, the pressure can be transmitted to the bladder neck and urethra in the same proportion, so as to keep the urethra pressure greater than the bladder pressure and prevent the outflow of urine (18). A number of studies $(19,20)$ have shown that timely and moderate Kegel exercise can achieve good results in the treatment of urinary incontinence after LRP, and this exercise is a safe treatment method, which can be used as the first choice for conservative treatment of urinary incontinence. However, Kegel exercise also has shortcomings, such as long treatment cycle, slow onset of action, monotonous action, and so on, which greatly reduce the compliance and enthusiasm of patients. In recent years, some researchers have added pelvic floor muscle rehabilitation exercises based on Kegel exercises, which emphasize core, respiration, and control (21). Studies have shown that such exercises are not only safe, but also greatly shorten the treatment period (22). The improvement of rehabilitation rate of urinary incontinence and the increase of exercise interest have fostered its wide promotion and application in maternal urinary incontinence (23). In view of this, this study formulated pelvic floor muscle rehabilitation exercise on the basis of Kegel exercise, which formulated 4 sets of movements, including inner thigh training, outer thigh training, hip training, and superman flight training.
In this study, according to the physiological conditions of patients at different stages after LRP surgery, the content of rehabilitation training was quantified step by step, and a graded rehabilitation training program was developed. Kegel exercise and pelvic floor muscle rehabilitation exercise were divided into 2 levels according to exercise intensity, so as to increase patients' confidence in continuous training and ensure the safety and feasibility of the program.

\section{It is of great significance to construct a pelvic floor muscle rehabilitation training program for patients undergoing LRP}

Urinary incontinence is the most common complication after LRP, and some patients will still have varying degrees of urinary incontinence within 1 year after surgery; however, most patients can significantly improve their urinary incontinence after positive pelvic floor muscle rehabilitation training, and only a very few patients need surgical intervention (15). The main causes of postoperative urinary incontinence are transient sphincter insufficiency, detrusor instability, and decreased bladder compliance during LRP, which can be recovered with scientific postoperative training (24). In order to reduce the trauma caused by surgery as much as possible, in addition to the fine operation during surgery, perioperative urine control technology should also be actively advocated in postoperative rehabilitation. However, in the multidisciplinary team, there is a shortage of clinicians in China, and the number of rehabilitation therapists is lower than the standard configuration, which makes it difficult to meet the needs of LRP patients' pelvic floor muscle rehabilitation training. Although an important member, the rehabilitation tasks of nurses have not been clearly defined. The formation of this program ensures that nurses, therapists, and doctors have clear and clear practical guidance to effectively carry out pelvic floor muscle rehabilitation, which is of great significance for promoting patient rehabilitation, developing multidisciplinary teams, and highlighting the value of each discipline. In addition, compared with the shortage of rehabilitation therapists and clinicians, nurses take care of patients for $24 \mathrm{~h}$, and are more actively involved in the guidance, supervision, and application of daily pelvic floor muscle rehabilitation training for patients. The LRP surgery has many advantages, such as less trauma and faster recovery, but because the anatomical position of the prostate is in a rich vascular cluster, postoperative hematoma forms easily, and bleeding can easily occur when a certain pressure 
is reached. Therefore, we must accurately grasp the training time point, and measure need to be promptly taken should bleeding occur. One of the common methods is bladder flushing, and it is recommended to refer to the continuous bladder flushing speed control card (25).

\section{Conclusions}

This study constructed a pelvic floor muscle rehabilitation training program for LRP patients through two rounds of expert consultation, including 3 first-level indicators (rehabilitation training evaluation, rehabilitation training advanced time and content, rehabilitation training form), 12 second-level indicators, and 53 third-level indicators. The consultation results were reliable, and the rehabilitation training program constructed was scientific, safe and feasible, which was suitable for the evaluation, planning and intervention of pelvic floor muscle rehabilitation training patients after LRP. It is important to note that the program is based on the cooperation of urologists, urological nurses and rehabilitation therapists, and has undergone systematic training and assessment. Next, we will carry out a randomized controlled study to evaluate the clinical application effect of the scheme.

\section{Acknowledgments}

The authors gratefully thank Prof. Yuhua Huang, Dr. Weijie Zhang, Dr. Zhixin Ling and Dr. Yuxin Lin (Department of Urology, the First Affiliated Hospital of Soochow University, Suzhou, China) for their kind help in quality control and data collection.

Funding: This study was supported by the Suzhou 32nd Batch of Science and Technology Development Plan (Medical and Health Technology Innovation) [2021] (No. SKJY2021065).

\section{Footnote}

Data Sharing Statement: Available at https://tcr.amegroups. com/article/view/10.21037/tcr-21-2738/dss

Conflicts of Interest: All authors have completed the ICMJE uniform disclosure form (available at https://tcr.amegroups. com/article/view/10.21037/tcr-21-2738/coif). The authors have no conflicts of interest to declare.

Ethical Statement: The authors are accountable for all aspects of the work in ensuring that questions related to the accuracy or integrity of any part of the work are appropriately investigated and resolved. All of the experts provided informed consent and volunteered to participate in the study. The study conformed to the provisions of the Declaration of Helsinki (as revised in 2013) and was approved by the Institutional. Review Board of The First Affiliated Hospital of Soochow University [approval number: (2021)336].

Open Access Statement: This is an Open Access article distributed in accordance with the Creative Commons Attribution-NonCommercial-NoDerivs 4.0 International License (CC BY-NC-ND 4.0), which permits the noncommercial replication and distribution of the article with the strict proviso that no changes or edits are made and the original work is properly cited (including links to both the formal publication through the relevant DOI and the license). See: https://creativecommons.org/licenses/by-nc-nd/4.0/.

\section{References}

1. Cheng Y, Li L, Qin Z, et al. Identification of castrationresistant prostate cancer-related hub genes using weighted gene co-expression network analysis. J Cell Mol Med 2020;24:8006-17.

2. Bin L. Tutorial for outline of the healthy. China 2030 plan (M). PMPH, 2021. Available online: https://link.springer. com/book/10.1007/978-981-32-9603-9

3. Sánchez-Salcedo R, Miranda-Castro R, de-Los-SantosÁlvarez N, et al. Dual electrochemical genosensor for early diagnosis of prostate cancer through lncRNAs detection. Biosens Bioelectron 2021;192:113520.

4. Mita K, Kobatake K, Kohada Y, et al. Laparoscopic radical prostatectomy of 926 patients at the Hiroshima endourological association. Nihon Hinyokika Gakkai Zasshi 2019;110:1-11.

5. Mottet N, Bellmunt J, Bolla M, et al. EAU-ESTROSIOG Guidelines on Prostate Cancer. Part 1: Screening, Diagnosis, and Local Treatment with Curative Intent. Eur Urol 2017;71:618-29.

6. Sciarra A, Viscuso P, Arditi A, et al. A biofeedback-guided programme or pelvic floor muscle electric stimulation can improve early recovery of urinary continence after radical prostatectomy: A meta-analysis and systematic review. Int J Clin Pract 2021;75:e14208.

7. Chang JI, Lam V, Patel MI. Preoperative Pelvic Floor Muscle Exercise and Postprostatectomy Incontinence: 
A Systematic Review and Meta-analysis. Eur Urol 2016;69:460-7.

8. Zhang AY, Bodner DR, Fu AZ, et al. Effects of Patient Centered Interventions on Persistent Urinary Incontinence after Prostate Cancer Treatment: A Randomized, Controlled Trial. J Urol 2015;194:1675-81.

9. Sarikaya S, Yildiz FG, Senocak C, et al. Urinary incontinence as a cause of depression and sexual dysfunction: Questionnaire-based study. Rev Int Androl 2020;18:50-4.

10. Qaseem A, Dallas P, Forciea MA, et al. Nonsurgical management of urinary incontinence in women: a clinical practice guideline from the American College of Physicians. Ann Intern Med 2014;161:429-40.

11. Woodley SJ, Boyle R, Cody JD, et al. Pelvic floor muscle training for prevention and treatment of urinary and faecal incontinence in antenatal and postnatal women. Cochrane Database Syst Rev 2017;12:CD007471.

12. Labrie J, Berghmans BL, Fischer K, et al. Surgery versus physiotherapy for stress urinary incontinence. $\mathrm{N} \mathrm{Engl} \mathrm{J}$ Med 2013;369:1124-33.

13. Brennen R, Frawley HC, Martin J, et al. Groupbased pelvic floor muscle training for all women during pregnancy is more cost-effective than postnatal training for women with urinary incontinence: costeffectiveness analysis of a systematic review. J Physiother 2021;67:105-14.

14. Nunes EFC, Sampaio LMM, Biasotto-Gonzalez DA, et al. Biofeedback for pelvic floor muscle training in women with stress urinary incontinence: a systematic review with meta-analysis. Physiotherapy 2019;105:10-23.

15. Anderson CA, Omar MI, Campbell SE, et al. Conservative management for postprostatectomy urinary incontinence. Cochrane Database Syst Rev 2015;1:CD001843.

16. Yang N, Ge X, Ye J, et al. Efficacy of acupuncture for urinary incontinence in middle-aged and elderly women: A systematic review and meta-analysis of randomized controlled trials. Eur J Obstet Gynecol Reprod Biol

Cite this article as: $M a \mathrm{ZZ}$, Zhang HB, Niu ME, Ding YH, Zhou Y, Yang Q, Wang JL, Zhu XW, Qian CY, Su M. Construction of pelvic floor muscle rehabilitation training program for patients undergoing laparoscopic radical prostatectomy. Transl Cancer Res 2022;11(2):392-402. doi: 10.21037/tcr-21-2738
2021;257:138-43.

17. Diviani N, van den Putte B, Giani S, et al. Low health literacy and evaluation of online health information: a systematic review of the literature. J Med Internet Res 2015;17:e112.

18. Kegel AH. Method and apparatus for indicate or observe progressive exercise of injured sphincter muscles. US, US2541520 A(P). 1951. Available online: https://www. freepatentsonline.com/2541520.html

19. Park SH, Kang CB, Jang SY, et al. Effect of Kegel exercise to prevent urinary and fecal incontinence in antenatal and postnatal women: systematic review. J Korean Acad Nurs 2013;43:420-30.

20. ohktar MS, Ibrahim F, Mohd Rozi NF, et al. A quantitative approach to measure women's sexual function using electromyography: a preliminary study of the Kegel exercise. Med Sci Monit 2013;19:1159-66.

21. Avila L, Neves ML, Abreu AR, et al. Cognitive functional therapy (CFT) compared with core training exercise (CTE) in patients with failed back surgery syndrome (FBSS): A study protocol for a randomized controlled trial. J Bodyw Mov Ther 2021;26:428-34.

22. Farzinmehr A, Moezzi A, Koohpayezadeh J. A Combination Training of Pelvic Floor Muscles and Core Muscles in Improvement of Stress Urinary Incontinence. J Neurosci 2013;31:5579-88.

23. Dumoulin C, Cacciari LP, Hay-Smith EJC. Pelvic floor muscle training versus no treatment, or inactive control treatments, for urinary incontinence in women. Cochrane Database Syst Rev 2018;10:CD005654.

24. Heydenreich M, Puta C, Gabriel HH, et al. Does trunk muscle training with an oscillating rod improve urinary incontinence after radical prostatectomy? A prospective randomized controlled trial. Clin Rehabil 2020;34:320-33.

25. Ma ZZ, Han YX, Wang WZ, et al. The use of a homemade rate adjustment card in patients with continuous bladder irrigation after transurethral resection of the prostate. Transl Androl Urol 2020;9:2227-34. 